\title{
Self-Efficacy as a Moderator of the Effects of Job-Search Workshops on Re-Employment: A Field Experiment ${ }^{1}$
}

\author{
ArIE SHIROM ${ }^{2}$ \\ Faculty of Management \\ Tel Aviv University
}

\author{
AMIRAM VinOKUR AND \\ RICHARD PRICE \\ Michigan Prevention Research Center, \\ Institute for Social Research \\ University of Michigan-Ann Arbor
}

\begin{abstract}
We investigated the additive and interactive effects of self-efficacy as a possible moderator of the effects of a job-search workshop on re-employment outcomes. We recruited 659 recently unemployed respondents and randomly assigned them to an experimental group invited to participate in the job-search workshop $(n=442)$, or a control group $(n=217)$. All respondents provided pretest data using selfadministered questionnaires, and posttest data using questionnaires mailed to them 1 and 6 months after the workshop. No direct effects of the intervention on re-employment outcomes were found. The pretest-posttest change in self-efficacy interacted with the experimental condition to predict 3 re-employment outcomes. However, only 1 of the 3 moderating effects found supported our prior expectation in this regard.
\end{abstract}

The primary purpose of the present research is to investigate the effects of an intervention, designed to help unemployed persons find new jobs, on the extent to which they achieve successful re-employment outcomes. We assessed the effects of the intervention in a randomized field experiment that allowed us to control for antecedent human capital variables that are known to influence employers' hiring decisions and job seekers' search efforts (cf. Vinokur, Schul, Vuori, \& Price, 2000). Based on the theoretical arguments and past research we will review later, we expected self-efficacy to moderate the effects of the intervention on re-employment outcomes. We decided to focus on self-efficacy because it represents a psychological resource likely to enhance effective coping with unemployment negative effects and favorable re-employment outcomes. We define favorable re-employment outcomes to

${ }^{1}$ This research was supported by the United States-Israel Binational Science Foundation Grant No. 94-49 (Principal Investigators: Arie Shirom, Richard H. Price, and Amiram Vinokur).

${ }^{2}$ Correspondence concerning this article should be addressed to Arie Shirom, Faculty of Management, Tel Aviv University, P.O. Box 39010, Tel Aviv 69978, Israel. E-mail: ashirom@, post.tau.ac.il 
include quantitative (e.g., being re-employed, duration of re-employment) and qualitative (e.g., re-employed person's assessment of the new job as a satisfying one) aspects of re-employment.

Most of the past research that has studied the moderating effects of self-efficacy has been conducted in small-scale laboratory studies using students. In addition, the research has often focused on emotional outcomes (e.g., reduction in anxiety), rather than on behavioral outcomes like re-employment outcomes (e.g., see Bandura \& Wood, 1989; Clark, Abrams, Niaura, Eaton, \& Rossi, 1991; Gist, Stevens, \& Bavetta, 1991; Ozer \& Bandura, 1990; Smith, 1989; Wood \& Bandura, 1989).

The present study is designed to test the external validity of self-efficacy as a mechanism leading to goal attainment in natural settings by focusing on an intervention program for unemployed persons designed to enhance their job-seeking skills and thereby promote their re-employment. This intervention program provides a good context for testing the aforementioned issue, for several reasons. First, unemployment has been rated among the top five stressful life events (Vinokur \& Caplan, 1987). Second, successful re-employment has been shown to depend on various conditions in the labor market, certain unchangeable demographic characteristics (e.g., age, gender, educational attainment), and certain relatively unchangeable occupational characteristics (e.g., an academic degree). However, there is additional evidence that has linked it to the intensity, persistence, and quality of job-search behaviors, likely to be affected by self-efficacy (Kanfer, Wanberg, \& Kantrowitz, 2001). Third, entering and re-entering the labor force, and experiencing job losses and periods of unemployment are events likely to appear in most people's life cycle. Consequently, we seek to make a practical contribution for both the affected individuals and for the economy as a whole by identifying the processes that facilitate successful re-employment. Fourth, the vast research literature concerning the impact of job loss and unemployment on workers' stress and mental health has documented the deleterious effects of unemployment.

A recent meta-analysis of 104 empirical studies (McKee-Ryan, Song, Wanberg, \& Kinicki, 2005) concluded that unemployed individuals had lower psychological and physical well-being than did their employed counterparts. Furthermore, McKee et al. found that within the unemployed samples, coping resources and strategies - including self-efficacy - displayed stronger relationships with mental health than did human capital or demographic variables. This literature also demonstrates the harmful impact of unemployment on the family (Barling, 1990). Therefore, it is our contention that a better understanding of successful job-search processes on the part of unemployed persons will have the potential of providing benefits to various health-related social programs. 


\section{Effects of Self-Efficacy on Re-Employment Outcomes}

An abundance of empirical findings has suggested that individuals able to cope effectively with behavioral change in stressful circumstances are endowed with certain social and personality resources. These resources include optimism (Scheier \& Carver, 1987, 1992), a sense of mastery (Pearlin \& Schooler, 1978), and general self-efficacy (Eden \& Kinnar, 1991; Tipton \& Worthington, 1984). In the current study, we focus on general self-efficacy, which refers to the individual's innate belief in his or her ability to perform a wide range of tasks in various challenging achievement situations (Bandura, 1997). The reason for focusing on general self-efficacy is that it is likely to have implications for people's work experiences across a broader range of contexts. People's judgments of their self-efficacy influence the initiation, intensity, and persistence of the behaviors that they undertake (Bandura, 1997).

Using self-efficacy as a possible mediator of the re-employment outcomes of a job-search workshop is advantageous because, theoretically, it is a dynamic construct that entails viewing individuals as active agents and is directly related to what individuals do in their job-search efforts. Compared with individuals who possess low self-efficacy, individuals with high selfefficacy perceive themselves as more capable of engaging in an effective job search and perceive re-employment as more controllable and imminent (Eden \& Aviram, 1993; Wanberg, 1997). There is evidence suggesting that positive expectations concerning re-employment of unemployed individuals with high self-efficacy may be self-fulfilling in that they tend to be more focused on their job search and devote more attention and effort to it, relative to unemployed persons who possess low self-efficacy (Leana \& Feldman, 1995; Wanberg, 1997).

A meta-analytic study of the effects of a variety of antecedent variables on re-employment outcomes found that self-efficacy was positively associated with obtaining employment (Kanfer et al., 2001). However, the corrected meta-correlation (.08) was not significant. Still, more recent studies-while conducted on job seekers, rather than on unemployed persons-have provided strong support to the relationship of self-efficacy with subsequent employment outcomes (Brown, Cober, Kane, Levy, \& Shalhoop, 2006; Cote, Saks, \& Zikic, 2006; Moynihan, Roehling, LePine, \& Boswell, 2003).

\section{Effects of a Job-Search Workshop Intervention on Re-Employment Outcomes}

In an effort to promote re-employment among the country's unemployed persons, the Israeli State Employment Service offered job-search workshops 
to unemployed persons. The job-search workshops were designed to promote a more effective job search by job seekers, and include some of the components built into the workshops offered to unemployed persons in other countries (e.g., Creed, Hicks, \& Machin, 1999; Vinokur, Price, \& Schul, 1995; Vinokur et al., 2000; Vuori \& Vesalainen, 1999) as preventive interventions. Such common components include providing information about the local labor market (e.g., Vuori \& Vesalainen, 1999), active learning of effective job-search skills (e.g., Vinokur et al., 1995), and enhancing participants' self-efficacy (e.g., Eden \& Aviram, 1993).

The present research is an effort to assess the effectiveness of these workshops in a randomized field study. The study's objective is to determine whether the job-search workshops intervention replicates the positive effects on re-employment outcomes that have been reported in other field experiments conducted on job-search workshops (e.g., Caplan, Vinokur, Price, \& van Ryn, 1989; Eden \& Aviram, 1993; Vinokur et al., 1995, 2000; Vinokur, van Ryn, Gramlich, \& Price, 1991; Vinokur \& Schul, 1997; Vuori \& Vesalainen, 1999). For example, Vinokur et al. $(1995,2000)$ reported significantly higher levels of re-employment outcomes among participants in the job-search workshops that they studied, as compared with control groups, 1 year and 2 years after the intervention.

Therefore, we propose the following hypothesis:

Hypothesis 1. Participants in the job-search intervention will have more beneficial re-employment outcomes relative to their control group counterparts.

\section{Self-Efficacy's Moderation of Effects of the Intervention on Re-Employment Outcomes}

Yet another objective of the present study is to assess the extent to which the intervention enhances self-efficacy levels among participants in it, relative to their counterparts in the control group. The objective was derived from the findings of several past field experiments conducted on the effects of jobsearch workshops (e.g., Creed et al., 1999; Eden \& Aviram, 1993; Vinokur \& Schul, 1997); namely, that enhanced sense of employment expectations, mastery, or self-efficacy were found among participants in the intervention.

According to Bandura (1997), self-efficacy beliefs are determined primarily by enactive mastery. Enactive mastery depends on both perceived and actual task performance, and is also affected by verbal persuasion from others, vicarious learning, and emotional arousal (Bandura, 1997). The intervention is expected to have a favorable effect on self-efficacy levels as a result 
of several components customarily incorporated in job-search workshops, including active learning of job-search skills, trainers acting as role models with respect to effective problem solving, and practicing the emotional coping skills that take place in job-search workshops (Vinokur et al., 1991, 1997, 2000). The following hypothesis is proposed:

Hypothesis 2. Participants in the job-search intervention will report higher levels of self-efficacy, relative to their control group counterparts.

The intervention-related change in self-efficacy is further expected to interact synergistically with the other components of the job-search workshops - including the job-search skills acquired, labor market information obtained, and mutual support processes in these workshops - to moderate the effects of the intervention on re-employment outcomes. Specifically, we expect the following:

Hypothesis 3. For those in the experimental condition, the change in their levels of self-efficacy (as assessed before and after the intervention) will be associated with significantly more favorable re-employment outcomes relative to their counterparts in the control group.

Self-efficacy is a critically important personal resource and, theoretically, is expected to facilitate the use of other coping resources (e.g., job-search skills) in one's goal-directed behaviors (Judge \& Bono, 2001). Past research has provided support to the argument that interventions that enhance individuals' self-efficacy are associated with the individuals' more persistent and more effortful attempts to implement newly acquired skills in the jobprocurement process (cf. Wenzel, 1993). Several studies have reported on analogous uses of self-efficacy as moderating the effects of field experiments (cf. Dvir, Eden, \& Banjo, 1995).

To pursue the objectives of the present study, we recruited 659 recently unemployed respondents from the Israeli State Employment Service offices. We randomized respondents into two groups: those invited to participate in the job-search skill enhancement workshops $(n=442)$, or a control group receiving self-instructional material $(n=219)$, oversampling respondents in the experimental group. We collected pretest data (Time 1; T1) using selfadministered questionnaires at the Employment Service offices. Time 2 (T2) and Time 3 (T3) follow-up questionnaires were mailed to respondents at intervals of 4 weeks and 6 months, respectively, following the week of the workshop to which they were randomly assigned as experimental or controlgroup respondents. 


\section{Method}

\section{Participants and Design Overview}

In the present study, the actual content and general mode of delivery of the job-search workshops were standardized in that both were specified in the contract signed between each for-profit firm offering the workshops and the Ministry of Labor and Social Welfare. Respondents were randomized into the aforementioned two groups in each location of the job-search workshops.

We did not have any control over either the training of the trainers or the training processes in the workshops. This feature of the current study stands in contrast to the design of other field experiments in which the workshops were designed and conducted by the investigators under stringent standards of quality control (e.g., Eden \& Aviram, 1993; Vinokur et al., 1995, 2000). This is a common feature in studies that have assessed the effectiveness of similar interventions in other countries (e.g., Creed et al., 1999; Vuori \& Vesalainen, 1999).

Based on written descriptions of the workshops provided to participants and the language of the public contract issued by the Ministry, the content and delivery of the job-search workshops resembled those described by Eden and Aviram (1993) and Vinokur et al. (1995, 2000), with the following exceptions. The job-search workshops under study placed less emphasis on principles of active learning and mutual support, and placed more emphasis on providing information on local labor-market conditions. The workshops were offered only in those areas of the country that were pre-defined by the Employment Service as being areas of high unemployment, in which the unemployment rate exceeded $10 \%$. For reasons connected with regulations governing the allocation of unemployment benefits in Israel, we excluded from the sample job seekers who had been unemployed for less than 10 weeks. As a result, participants in the job-search workshops had been unemployed for an average of 6.52 months $(S D=0.37, M d n=4.00)$.

We used the screening criteria adopted by Vinokur et al. (1995). Workers who are officially certified as being unemployed are eligible for employment benefits, but must present themselves in person at the employment office at least once a week. Each individual reports to the placement officer to whom he or she has been assigned, usually on the same day of the week (cf. Eden \& Aviram, 1993).

The screening and completion of the pretest (T1) questionnaire took place when job seekers routinely came to register with the local branches of the Employment Service. The investigators had full control over randomization of participants to the experimental and control groups. They also enjoyed complete discretion regarding the administration of $\mathrm{T} 2$ and $\mathrm{T} 3$ posttest ques- 


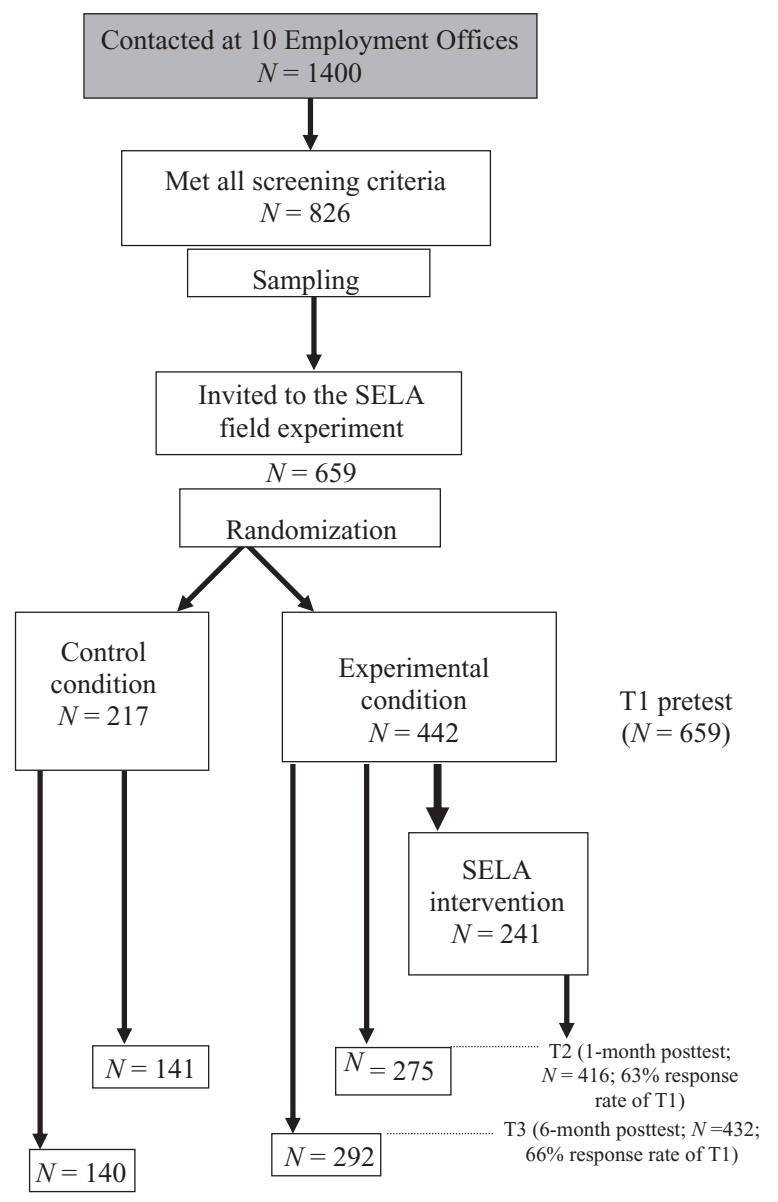

Figure 1. Research design of the intervention.

tionnaires. An overview of the study design - including the steps involved in screening and recruitment, pretest, and posttest data collections, and the response rates achieved at each stage - is displayed in Figure 1.

\section{Recruitment Procedure}

Respondents were recruited from 10 offices of the Israeli Employment Service. Trained interviewers approached 1,400 potential respondents while they waited in the unemployment offices, and briefly inquired whether they were unemployed and looking for a job. Over 574 of those contacted were 
ineligible for participation because they were new entrants to the labor market within 5 months of their discharge from compulsory military service, new immigrants who did not know Hebrew well enough to answer the research questionnaires, individuals who had already been re-employed, pregnant women who were due to deliver within the next 3 months, or people who were merely accompanying others in line. Thus, of those contacted, only 826 (Figure 1, Box 2) met the basic initial criteria, which also included the condition that respondents were not planning to retire within the next 2 years.

Those individuals who met all of the initial criteria were invited to participate in the field experiment and were asked additional questions to determine their final eligibility. Only 659 (Figure 1, Box 3) met all of the eligibility criteria for participation in the field experiment. Of the two final exclusion criteria, the first was that the respondent had lost his or her job and had been unemployed for over 10 weeks. Respondents were told about two programs that were being offered by the Employment Service on how to look for jobs. One program was described as a 5-day (Sunday through Thursday) all-day seminar series (i.e., experimental condition group), while the other was described as a self-guided booklet program (i.e., control condition group). To ensure equal motivation to enter either group, only persons who expressed no preference were randomly assigned to the experimental and control groups: This was the second exclusion criterion.

\section{Randomization Procedure and Experimental Design}

A computerized randomization procedure was used to allocate respondents to the control condition or the experimental condition. Those who were assigned to the experimental condition received an invitation to participate in the job-search workshop. Those who were assigned to the control condition were mailed two booklets that contain the core content of the job-search skills covered by the workshops. The two booklets, prepared by the Employment Service, were freely available to unemployed persons in each office. Mailing the two booklets to those in the control group does not represent any significant change in the naturally occurring processes of the Employment Service offices, apart from the convenience of receiving the booklets by mail. Respondents assigned to either the control or experimental groups received the equivalent of a $\$ 10$ check in local currency as payment for completing each of the research questionnaires.

As indicated, the experimental condition consisted of five full-day sessions that were conducted over a 1-week period. The topics include examples and exercises in identifying and conveying one's job-relevant skills, using social 
networks to obtain job leads, contacting potential employers, preparing job applications and résumés, and successfully going through a job interview. Seminar trainers were mostly experienced group leaders who were employed by the firms that offered the job-search workshops.

Among those who were assigned to the experimental condition and who became study participants by returning the T1 pretest questionnaire (Figure $1 ; n=442)$, there were $45 \%(n=201)$ who failed to show up for the intervention but continued to provide follow-up data at T2 and T3. We had expected this rate of intervention dropout (cf. Caplan et al., 1989; Vinokur et al., 1995). Therefore, in the randomization stage, we allocated twice as many respondents to the experimental group. Of those who appeared and who responded to our T2 posttest questionnaire, $85 \%$ attended all five sessions.

The control condition consisted of the two booklets mailed to participants after they had been assigned to the control condition. The booklets contain useful information, but are abbreviated in comparison to self-help books that are available on job search.

\section{Data Collection}

Respondents who were eligible for participation were requested to complete our T1 pretest questionnaire at the employment office while waiting their turn to be interviewed by an Employment Service official. The questionnaire's cover letter includes our guarantee of confidentiality, and an assurance that the study is not connected with the Employment Office. Subsequently, all those who completed $\mathrm{T} 1$ questionnaires and who were found to be eligible for participation were randomized into one of the experimental conditions.

T2 and T3 follow-up questionnaires were mailed to respondents 1 and 6 months, respectively, after the week of the intervention seminar in which they were categorized as either experimental or control-group respondents. Completed questionnaires were acknowledged with a thank-you letter and a check for the equivalent of $\$ 10$ in local currency.

To assess the strength of the intervention, as well as a manipulation check, workshop participants (according to lists of participants obtained from the Employment Service following each workshop) were asked to complete a brief workshop assessment sheet in the T2 posttest questionnaire. Respondents who did not return the questionnaires within 4 weeks were sent an offer of a $\$ 15$ bonus check to be issued upon receipt of their completed questionnaires. This latter incentive, which began at the midpoint of the T2 follow-up, resulted in a substantial increase in response rates (about 20\%), and accounted for the higher $\mathrm{T} 3$ than $\mathrm{T} 2$ response rate. 
Table 1

Descriptive Data on Study Variables

\begin{tabular}{|c|c|c|c|c|c|c|}
\hline \multirow[b]{2}{*}{ Variable } & \multicolumn{3}{|c|}{ Pretest (T1) } & \multicolumn{3}{|c|}{ Posttest (T3) } \\
\hline & $M$ & $S D$ & $\alpha$ & $M$ & $S D$ & $\alpha$ \\
\hline \multicolumn{7}{|c|}{ Re-employment outcomes } \\
\hline Job satisfaction ${ }^{\mathrm{ab}}$ & 3.34 & 0.81 & .82 & 3.36 & 0.73 & .84 \\
\hline Months employed ${ }^{\mathrm{a}}$ & N/A & & & 4.54 & 2.74 & \\
\hline Weekly work hours ${ }^{\mathrm{a}}$ & N/A & & & 39.82 & 14.38 & \\
\hline \multicolumn{7}{|c|}{ Predictors and moderators } \\
\hline Self-efficacy & 3.65 & 0.64 & .86 & 3.74 & 0.66 & .88 \\
\hline
\end{tabular}

Note. $\mathrm{T} 1=$ Time $1 ; \mathrm{T} 3=$ Time 3 (6-month follow-up). N/A = data on this variable were not collected at T1. $N$ for T1 and T3=approx. 425 .

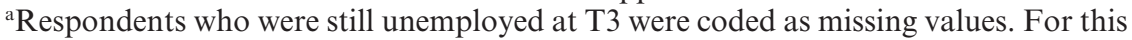
variable, $N=$ approx. 175 . 'Pretest values for this variable relate to respondents' last job held.

\section{Measures}

Except for demographic and certain re-employment variables, all of the variables in the current study were assessed as constructs with multi-item measures. We used a 5-point Likert-type format for most of the measures in this study. Ratings on the items included in each measure were averaged to create an index for each T1, T2, and T3 survey. Most of the measures were used in previous studies of unemployed samples (e.g., see Caplan et al., 1989; Price, van Ryn, \& Vinokur, 1992; Vinokur \& Caplan, 1987). Most of these measures have been translated into Hebrew and validated in studies conducted in Israel.

We will present a description of the subset of measures that were used in the current study. Descriptive data on the means, standard deviations, and Cronbach's alpha reliability coefficients for the measures are presented in Table $1 .^{3}$

Demographics. Demographics were assessed using standard survey questions. The questions were designed to collect information on participants' age, gender, education, marital status, occupation, personal and total family

${ }^{3}$ Details on the full set of measures and copies of the Hebrew language questionnaires are available from the authors upon request. 
income, dependents, ethnic background, and characteristics of each individual's last job (e.g., number of hours of work per week, wage rate).

Self-efficacy. The general self-efficacy measure was based on earlier measures developed by Sherer and Adams (1983) as translated, pretested, and field-tested by Eden and Kinnar (1991); and as used for unemployed persons by Eden and Aviram (1993). The measure consists of 17 items that are rated on a 5-point scale ranging from 1 (strongly agree) to 5 (strongly disagree).

Re-employment. In keeping with the conceptual approach to re-employment in earlier field experiments (e.g., Vinokur et al., 1995), we used four different criteria of re-employment. The first criterion we used was the simple dichotomy of unemployed versus re-employed. A respondent had to work 10 hours or more per week to be classified as re-employed. Persons working fewer than 10 hours per week were classified as not re-employed. The vast majority of the re-employed individuals worked in full-time jobs. Thus, this objective definition resulted in reclassifying only 9 respondents who actually worked fewer than 10 hours as not re-employed.

In addition to this dichotomy, we also used three qualitative measures that tap different aspects of the quality of re-employment: reported number of work hours per week, duration of employment in months, and quality of the new job found as re-employment criteria. The latter measure consists of respondents' assessment of job satisfaction. The job satisfaction measure consists of nine items, each representing a facet of the job, such as superior, peers, employing organization, salary, and variety at work. Responses were rated on a 5-point scale ranging from 1 (very dissatisfied) to 5 (very satisfied). In keeping with the practice adopted by other researchers (e.g., Vinokur et al., 1995), the unemployed were not included in analyses that concerned the four qualitative measures of re-employment.

Intervention indexes. We constructed four different indexes on the basis of the T2 posttest to assess the integrity and strength of the intervention. Workshop satisfaction consists of four items gauging respondents' overall satisfaction with different facets of the workshop they had attended, including contents, process, and trainer. The items were rated on a 5-point scale ranging from 1 (very dissatisfied) to 5 (very satisfied; $\alpha=.84$ ).

Workshop learning experience is a seven-item measure constructed to tap participants' evaluation of specific skills that were improved by workshop participation. The skills assessed include interviewing, contacting prospective employers, completing employment forms, and coping with the status of unemployment. The items were rated on a 5-point scale ranging from 1 (improved to a very small extent) to 5 (improved to a very great extent; $\alpha=.92$.

Workshop learning climate is a seven-item measure that taps the learning climate and processes in the workshop, including items related to question-asking ability, attentiveness of trainers, delivery of the material, and 
inspiration by the trainer. The items were rated on a 5-point scale ranging from 1 (to a very small extent) to 5 (to a very large extent; $\alpha=.84$ ). The same scale was used to measure skills acquired, which is the extent to which specific skills were actually learned during the workshop. The seven-item index includes the following skills: preparing a résumé, impressing employers with specific qualifications, contacting employers, and using friendship networks to obtain employment leads $(\alpha=.90)$.

\section{Sample Demographic Characteristics}

We did not include short-term unemployed, new entrants to the labor market, and unemployed youth under the age of 20 in the sample, who amounted to about one third of the unemployed population at the time of the study. The median age in our sample was 31.2 years $(M=33.2, S D=9.1)$. The sample consists of 33\% males, 35\% unemployed persons born outside of Israel (with a mean of 25 years of residence in the country), $34 \%$ married, and $76 \%$ having at least one dependent living with them in the same household.

On average, respondents in our sample had been unemployed for 6.50 months $(S D=3.44, M d n=4.00)$. The unemployed population who registered with the offices of the Employment Service during the period of the study had a mean age of 30.4 years; included $58 \%$ males and $44 \%$ married; and had been looking for a job for about 3 months. In our sample, educational background was as follows: Only $15 \%$ had not completed high school, $56 \%$ had a high school education, $11 \%$ had some college education, $4 \%$ had 4 years of college education, and $15 \%$ had some form of high school level or post high school level religious schooling. Respondents were mostly (52\%) unskilled workers, with only $5 \%$ classifying their occupation as requiring an academic degree. On average, they had worked 3.88 years $(S D=4.91)$ on their last job, and 41.02 hours per week $(S D=14.77)$.

\section{Response Rates, Attrition, and Effectiveness of Randomization}

Of the 659 individuals who enrolled in the study, $416(63 \%)$ completed T2 questionnaires, while $432(66 \%)$ completed T3 questionnaires. The higher response rate at $\mathrm{T} 3$ compared with $\mathrm{T} 2$ was the result of additional follow-up contacts and higher respondent pay. Males were significantly more likely to drop out of the study by not returning the T2 and T3 questionnaires. ${ }^{4} \mathrm{In}$

${ }^{4}$ The results of these analyses, not presented here, are available from the authors upon request. 
addition, T1 dropouts were significantly less depressed, relative to respondents at T2 $(M=1.86$ vs. 2.04$), t(412)=2.81, p<.005$; and had been unemployed for a shorter period of time $(M$ months unemployed $=5.63$ vs. 6.99$)$, $t(429)=1.93, p<.05$. However, there were no differences in attrition rates between the experimental and control conditions.

We systematically tested for significant interactions between attrition and the experimental conditions for each of the following primarily demographic variables: age, number of weeks since job loss, educational attainment (schooling), number of dependent persons living with the respondent, place of birth, total salary, and number of hours worked at the last job. None of these interactions was significant. In addition, there was no significant interaction between attrition and the experimental condition in predicting either of the study's criteria or predictors. There were no significant differences in any of the T1 variables between respondents in the experimental and control conditions. Consequently, the integrity of the randomization to experimental and control conditions was fully preserved (Hansen, Collins, Malotte, Johnson, \& Fielding, 1985).

To test the possible bias introduced by selective attrition from T1 to T3, we used logistic regression analysis. In this analysis, we predicted attrition (represented by a dummy variable in which $0=\mathrm{T} 1+\mathrm{T} 3$ respondents, and $1=$ T1-only respondents) by either of the two sets of predictors listed earlier. Among the demographic variables, only age was a significant predictor. Compared to respondents who provided data for the T3 follow-up, dropouts were significantly older ( 38.5 vs. 31.9 years; $p<.01)$.

Among the set of predictors used, only T1 depression was a significant predictor. Dropouts reported being less depressed. We tested for interaction effects between dropout rate and the experimental conditions on all of the aforementioned variables. ${ }^{5}$ No statistically significant interaction effect was found for either T2 or T3 dropouts. Following Hansen et al. (1985), we concluded that differential attrition rates could not affect internal validity of the results.

\section{Results}

\section{Manipulation Checks on Intervention Integrity and Strength}

Out of the 442 job seekers assigned to the experimental condition and invited to the job-search workshop, 241 (55\%) participated in the interven-

\footnotetext{
${ }^{5}$ Including $\mathrm{T} 1$ levels of the respective predictors in the regressions not only allowed us to test for changes in their levels over time from $\mathrm{T} 1$ to $\mathrm{T} 3$, but it also helped to control for any unspecified correlates of T1 predictors (Pedhazur, 1982).
} 
tion. Of these 241 participants, $92 \%$ attended at least four of the five sessions. Thus, the mean number of sessions attended was 4.82 .

Among the 292 members of the experimental group who responded to our T3 posttest, $186(64 \%)$ attended the workshop. Using the T2 questionnaire, $159(66 \%)$ of those who attended the workshop after responding to the T1 questionnaire reported their evaluations and experiences. Their evaluations provide evidence of the integrity and strength of the intervention and its immediate impact. Mean workshop satisfaction was $4.26(S D=0.74)$, indicating that most participants were very satisfied. For the workshop as a learning experience measure, the mean was $4.08(S D=0.70)$; again, positively slanted. The mean for workshop learning experience was $3.32(S D=1.02)$, and that of the measure of skills acquired was $3.95(S D=0.76)$. These are indicative of favorable evaluations of skills learned in the workshop.

\section{Correlation Analysis}

Table 2 represents the matrix of intercorrelations among the study's variables, separately for T1 and T3. Job satisfaction and self-efficacy were moderately correlated, as were the pretest and posttest measurements of self-efficacy. The experimental condition, represented by a dummy variable, did not correlate with any of the other variables in Table 2 . T1 self-efficacy was positively correlated with T3 re-employment outcomes $(r=.12, .19$, and .11 , with duration of re-employment, number of work hours per week, and job satisfaction, respectively), but only its correlation with number of work hours per week at T3 was significant $(p<.05)$. With one exception (mentioned later), among the potential control variables, gender, age, educational attainment, and a new immigrant status did not interact with the experimental condition in predicting either of the re-employment criteria. Also, with the exception of gender, none of the variables proved to be a significant predictor of re-employment in the logistic regressions predicting the dichotomy of re-employed versus unemployed at T3.

The one exception to the aforementioned pattern of results is presented in Table 3. Gender interacted with the experimental condition in predicting T3 re-employment. The likelihood of T3 re-employment increased $(b=.57$, Exp. $b=1.77, p<.05$ ) for $\mathrm{T} 1$ unemployed females in the experimental group. However, as noted, we were not able to replicate this interaction for either of the other re-employment criteria.

\section{Analyses of Experimental Effects of the Intervention}

To preserve the integrity of the randomized design and to avoid selection bias (Cook \& Campbell, 1979), our analyses included all respondents assigned 
Table 2

Intercorrelations Among Experimental Condition, Re-Employment Outcomes, Self-Efficacy Measures, and Sociodemographic Controls at T1, T3, and Autocorrelations

\begin{tabular}{|c|c|c|c|c|c|c|c|c|}
\hline Variable & 1 & 2 & 3 & 4 & 5 & 6 & 7 & 8 \\
\hline $\begin{array}{l}\text { 1. Experimental } \\
\text { condition }\end{array}$ & 1.00 & -.06 & -.01 & -.03 & .05 & -.11 & -.11 & -.01 \\
\hline $\begin{array}{l}\text { 2. Job } \\
\text { satisfaction }^{\mathrm{a}}\end{array}$ & .04 & - & .02 & .06 & $.31 *$ & -.09 & .09 & -.10 \\
\hline $\begin{array}{l}\text { 3. Months } \\
\text { employed }^{\text {a }}\end{array}$ & N/A & N/A & - & .02 & .06 & $.18^{*}$ & -.02 & .04 \\
\hline $\begin{array}{l}\text { 4. Weekly work } \\
\text { hours }^{\mathrm{a}}\end{array}$ & N/A & N/A & N/A & - & $.19^{*}$ & -.02 & -.10 & $.34 *$ \\
\hline 5. Self-efficacy & -.05 & .12 & N/A & N/A & $.56^{*}$ & -.02 & .06 & -.01 \\
\hline 6. Age & -.06 & .10 & N/A & N/A & -.09 & 1.00 & $-.20 *$ & .13 \\
\hline $\begin{array}{l}\text { 7. Educational } \\
\text { attainment }\end{array}$ & -.06 & -.05 & N/A & N/A & -.09 & -.15 & 1.00 & -.08 \\
\hline 8. Gender & -.10 & -.05 & N/A & N/A & -.01 & .08 & -.12 & 1.00 \\
\hline
\end{tabular}

Note. $\mathrm{T} 1=$ Time $1 ; \mathrm{T} 3=$ Time 3 (6-month follow-up). N/A = data on this variable were not collected at T1. T1 values appear below the diagonal, T3 values appear above the diagonal, and autocorrelations appear in boldface on the diagonal. Ns for computed correlations range from 175 to 432 . Condition: $0=$ control; $1=$ experimental. Gender: $0=$ male; $1=$ female.

${ }^{a}$ Respondents who were still unemployed at $\mathrm{T} 3$ were coded as missing values. For this variable, $N=$ approx. 175 .

$* p<.05$.

to the experimental group, regardless of whether or not they subsequently appeared and participated in the intervention workshop (cf. Vinokur et al., 1995, 2000). At T3, 55\% of the sample was re-employed, predominantly in full-time jobs ( $M$ weekly work hours $=39.1, S D=1.3)$. Re-employed individuals reported a mean employment period of 4.7 months (mode $=4.0$ ), indicating that the average period of unemployment from the $\mathrm{T} 1$ measurement was approximately 2 months. These characteristics of re-employment led to our decision to use logistic regressions with the dichotomous variable of re-employed versus unemployed at $\mathrm{T} 3$ as the criterion.

With the exception of the re-employed versus unemployed dichotomy at T3, we tested Hypothesis 1 concerning the main effects of the intervention on 
Table 3

Logistic Regression: T3 Employment Status Regressed on T1 Demographics

\begin{tabular}{lcclll}
\hline & \multicolumn{2}{c}{ Step 1} & & \multicolumn{2}{c}{ Step 2 } \\
\cline { 2 - 3 } \cline { 5 - 6 } T1 predictor & Exp. $b$ & $b$ & & Exp. $b$ & $b$ \\
\hline Gender & 1.27 & .24 & & 0.70 & -.37 \\
Age (in years) & 0.98 & -.02 & & 0.98 & -.02 \\
Experimental condition (E) & 0.95 & -.06 & & 0.67 & -.04 \\
E $\times$ Gender & & & & $2.57^{*}$ & .94 \\
\hline
\end{tabular}

Note. $\mathrm{T} 1=$ Time $1 ; \mathrm{T} 3=$ Time 3 . T3 employment status: $0=$ unemployed; $1=$ reemployed. Gender: $0=$ male; $1=$ female. Condition: $0=$ control; $1=$ experimental. For Step 1, $\chi^{2} \Delta(3, N=346)=2.69, n s$. For Step 2, $\chi^{2} \Delta(1, N=345)=3.80, p<.05$. Percentage of correct predictions for the final model was $57 \%$. Cox-Snell $R^{2}=.03$, $\chi^{2}(4, N=342)=6.49, p=.15 . b=$ logistic regression coefficient for each step; and Exp. $b=$ its logistic exponent.

$* p<.05$, two-tailed.

the re-employment criteria by using ANOVA. In all of the analyses, the intervention-control dichotomy was used as the predictor. No support for this hypothesis was found. ${ }^{6}$

We used logistic regression analysis to test all hypotheses concerning the dichotomous criterion of re-employed versus unemployed at T3. As is evident from Table 3, allocation to the control condition tended to decrease, albeit insignificantly, the likelihood of re-employment $(b=-.37$, Exp. $b=.69, n s)$. Hence, we concluded that the re-employment criteria were not significantly affected by the intervention, and thus Hypothesis 1 was not supported.

We next tested Hypothesis 2 concerning the main effects of the intervention on self-efficacy. For self-efficacy, there was no significant mean difference in T3 between participants in the control and experimental groups. For the group of respondents in the experimental condition, there was no significant difference in self-efficacy between T1 and T2. No support for the hypothesis was obtained in the regression analysis in which we attempted to predict T3 self-efficacy by the intervention, T1 self-efficacy, and the interaction between the two predictors. ${ }^{7}$

In evaluating these results, it should be remembered that only about $55 \%$ of the job seekers assigned and invited to the intervention actually appeared

${ }^{6}$ Information is available from the authors upon request.

${ }^{7}$ Information is available from the authors upon request. 
and participated in the workshops. That is, slightly more than half of the experimental group received the intervention. Our decision to analyze the data according to how participants were assigned has the advantage of preserving the integrity of the random assignment, but suffers from the drawback of describing the effects of the assignment to the intervention, rather than of the intervention itself (cf. Shadish, 2002).

To account for nonparticipation, we need an estimate of the strength of the results for the actual workshop participants, as compared with their counterparts in the control group. We followed Bloom's (1984) estimation procedure and calculated an adjusted effect size for the difference between intervention participants and their control group counterparts. We calculated the adjusted effect size by multiplying the effect size by a factor of 1.82 , which is the ratio of 1 divided by the participation rate of 0.55 . The value of 1.82 represents the dilution factor for the intervention dosage in the total experimental group. The adjustment is a correction for this dilution factor. A methodological study demonstrated that such a correction provides a very close estimate to the results received using a more robust procedure based on Rubin's causal model (cf. Little \& Yau, 1998). Considering the re-employment criteria - and with the exception of the dichotomy of re-employed versus unemployed at T3 - none of the adjusted effect sizes reached significance. ${ }^{8}$ Taken together, these results do not support Hypothesis 1.

Table 4 presents the results of the tests for Hypothesis 3, which deals with the interactive effects of the intervention and the T3 change selfefficacy on the criteria. In all regressions, we entered the experimental condition in the first step. We then controlled for age, gender, and educational attainment, but retained in the regression only those control variables that significantly predicted the respective re-employment criteria. Subsequently, we entered the baseline level of self-efficacy, then T3 self-efficacy (which thus represented the change in self-efficacy from T1 to T3; cf. Twisk, 2003), and then the interactive term of the experimental condition multiplied by T3 self-efficacy.

Self-efficacy scores were all centered, to reduce multicollinearity. A significant interaction term represents support for the moderating effect of the change in self-efficacy from $\mathrm{T} 1$ to $\mathrm{T} 3$ on the effects of the intervention on the respective re-employment criterion. Consistently, all three reemployment criteria used in Table 4 -namely, weekly work hours, months employed, and job satisfaction - were significantly predicted by the interaction of T3 self-efficacy with the experimental condition after controlling for T1 self-efficacy.

${ }^{8}$ Information is available from the authors upon request. 
Table 4

Hierarchical Moderated Multiple Regression Analyses Evaluating Moderating Effect of Experimental Condition on Prediction of Re-Employment Outcomes by Self-Efficacy Measures

\begin{tabular}{lccrr}
\hline Predictor & Intercept & $B$ & $S E B$ & $\beta$ \\
\hline Job satisfaction, T3 (adj. $\left.R^{2}=.07\right)$ & 3.44 & & & \\
Experimental condition (E) & & -0.12 & 0.11 & -.08 \\
Self-efficacy, T1 & & 0.07 & 0.14 & .06 \\
Self-efficacy, T3 & & $0.35^{*}$ & 0.09 & .32 \\
E $\times$ Self-Efficacy, T3 & $-0.23^{* a}$ & 0.12 & -.16 \\
Duration of employment, T3 & 4.60 & & & \\
$\quad$ in months; adj. $\left.R^{2}=.04\right)$ & & & & \\
Experimental condition (E) & & 0.02 & 0.32 & .01 \\
Age & & -0.47 & 0.02 & .17 \\
Self-efficacy, T1 & & -0.61 & 0.41 & -.09 \\
Self-efficacy, T3 & $1.59 *$ & 0.67 & .29 \\
E $\times$ Self-Efficacy, T3 & & & \\
Weekly work hours, T3 (adj. $\left.R^{2}=.15\right)$ & 36.44 & & & \\
Experimental condition (E) & & -0.24 & 2.18 & -.01 \\
Gender & & $10.70^{*}$ & 2.18 & -.35 \\
Self-efficacy, T1 & -0.80 & 1.92 & -.04 \\
Self-efficacy, T3 & $8.71 *$ & 2.75 & .40 \\
E $\times$ Self-Efficacy, T3 & & $-6.52^{*}$ & 3.15 & -.20 \\
\hline
\end{tabular}

Note. $N=$ approx. $176 . \mathrm{T} 1=$ Time $1 ; \mathrm{T} 3=$ Time 3 . Respondents who were still unemployed at T3 were coded as missing values. $B=$ unstandardized partial regression coefficient; $S E B=$ standard error of unstandardized partial regression coefficient; $\beta=$ standardized partial regression coefficient. For each regression, the value of the intercept was derived from the full moderated multiple regression equation. Condition: 0 = control; 1 = experimental.

${ }^{\mathrm{a}}$ Coefficient of the interactive term was significant at $p<.07$.

$* p<.05$.

These interactions were plotted according to the method described by Aiken and West (1991). Figures 2, 3, and 4 provide a graphic interpretation of the significant interactions. The interaction of T3 self-efficacy and the experimental condition in predicting duration of employment (Figure 3) was found to be disordinal in shape. The two regression lines crossed each for the 


\section{SHIROM ET AL.}

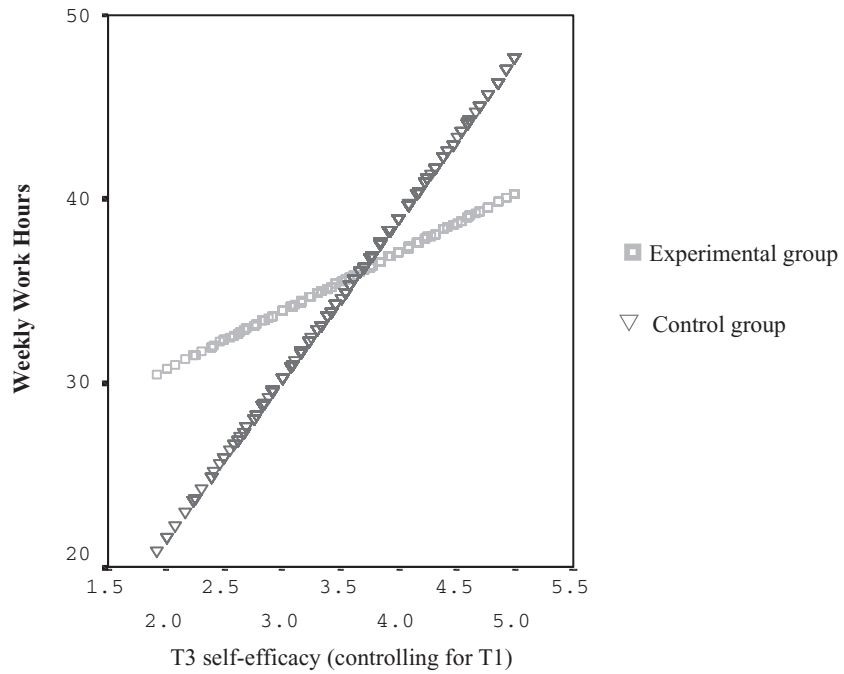

Figure 2. Interaction between $\mathrm{T} 3$ self-efficacy (controlling for T1) and the intervention in predicting T3 weekly work hours.

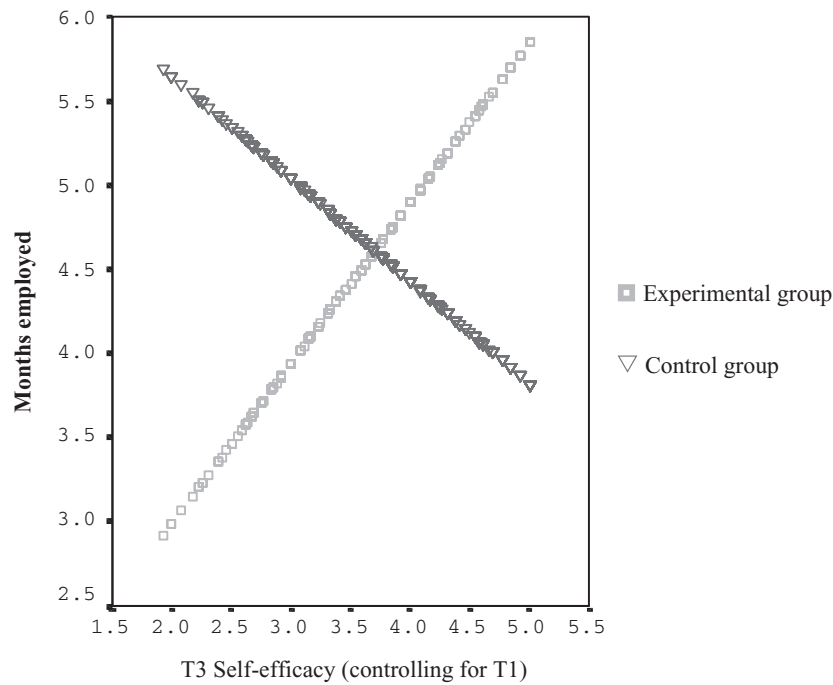

Figure 3. Interaction between T3 self-efficacy (controlling for T1) and the intervention in predicting $\mathrm{T} 3$ duration of employment (in months). 


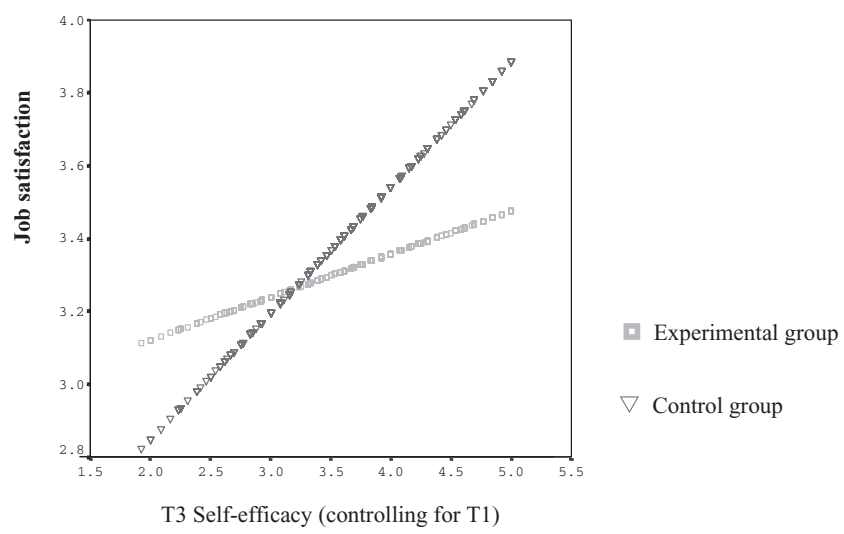

Figure 4. Interaction between T3 self-efficacy (controlling for T1) and the intervention in predicting T3 job satisfaction.

experimental and control conditions, respectively. For the intervention, the larger the change from $\mathrm{T} 1$ to $\mathrm{T} 3$, the more pronounced the effect of this change on subsequent duration of employment, while the opposite was correct for the control group, thus providing support to Hypothesis 3.

Figures 2 and 4 suggest that for those in the experimental condition and those in the control condition, the larger the change from T1 to T3 in self-efficacy, the higher the likelihood of participants in either group finding a higher quality job in terms of weekly work hours (Figure 2) and job satisfaction (Figure 4). However, Figures 2 and 4 indicate that there was no clear leverage obtained by those in the intervention group, relative to those in the control group. Therefore, we concluded that there was only partial and inconsistent support for Hypothesis 3.

\section{Discussion}

There is evidence that interventions that successfully promote faster re-employment or help unemployed persons obtain quality jobs enhance the efficiency of the labor market (Davidson \& Woodbury, 1993). The present study did not find any evidence of the direct effects of the intervention on re-employment outcomes or on self-efficacy for those in the experimental condition.

The pretest-posttest change in self-efficacy was found to interact with the intervention in influencing re-employment criteria. This is indicated by the three significant interactions between T3 measures of self-efficacy (control- 
ling for T1 self-efficacy) and the experimental condition in predicting the three qualitative re-employment criteria. However, only one of the three interactions provided clear support to Hypothesis 3. For participants in the experimental group, the higher their T3 level of self-efficacy (controlling for T1 self-efficacy), the faster was their re-employment, while the opposite held for those in the control group. This is supportive of the differential effect of the intervention, expected by Hypothesis 3. However, the other two interactive terms found, when plotted, did not support this hypothesis, leading us to conclude that it was only partly supported.

We will discuss some possible reasons that explain the lack of support for the intervention's effects on re-employment outcomes. There are, however, several possible explanations for the disconfirmation of Hypothesis 1, which we reject as inappropriate or irrelevant to the present study. Successful re-employment depends on several key factors. First, it depends on certain unchangeable demographic characteristics (e.g., age, gender, educational level). In this study, we did not discover any demographic characteristics that differed significantly between the experimental and control groups. Furthermore, with one exception, demographic characteristics did not interact with the experimental condition to explain either of the re-employment outcomes. The only exception we found was the interaction of gender with the experimental condition in the prediction of re-employment.

Second, re-employment is dependent on various conditions in the labor market (e.g., unemployment rate). Since the current study was limited to development towns in Israel's peripheral areas where the unemployment rate exceeds $10 \%$, this characteristic of the labor market can be regarded as controlled.

Third, in most instances, self-motivation and mobilization of personal and social skills to engage in job-search behavior are required to gain employment. Since the intervention had an insignificant long-term effect on self-efficacy, this could not be the mechanism explaining our failure to support Hypothesis 1.

\section{Comparison With Earlier Field Experiments}

What could explain our failure to replicate findings of earlier field experiments (e.g., Eden \& Aviram, 1993; Vinokur et al., 1995, 2000), in that the intervention was not found to have a direct effect on re-employment outcomes? A major difference between the present study and these earlier field experiments is the duration of unemployment in the respective samples. Briefly, the present study covered relatively long-term unemployed persons, who had experienced unemployment for over 10 weeks ( $M=6.5$ months), 
whereas the group of earlier studies focused on newly unemployed persons, who had been unemployed for less than 13 weeks (Vinokur et al., 1995, 2000) and a median of 8 weeks' unemployment (Eden \& Aviram, 1993).

A number of unemployment researchers have suggested stage models to explain the effects of duration of unemployment on psychological distress (Feather, 1990). These models assume that the initial period of unemployment is characterized by an optimistic outlook and active job search (Winefield \& Tiggemann, 1990). Many long-term unemployed persons develop a work-inhibition syndrome (Payne \& Jones, 1987) and engage in withdrawal tactics as their preferred coping style (Patton \& Donohue, 1998). Longitudinal studies of length of unemployment relationship with psychological distress have found that psychological distress increases up to around 6 or 9 months of continuous unemployment (Warr \& Jackson, 1987; Winefield \& Tiggemann, 1990). Thus, participants in the present study are likely to be more discouraged than their counterparts in the aforementioned field experiments; therefore, direct effects on re-employment outcomes were more difficult to obtain by means of the job-search workshops.

Yet another major difference concerns the content and delivery of the respective workshops. We know, from written reports submitted by the firms delivering the job-search workshops intervention under study, that the workshops were based on the acquisition of effective job-seeking skills. The same source indicated that workshop participants utilized the jobsearch skills they had acquired in the local labor market. These components had been included in the public contract that the firms were obligated to implement. However, in the design of the workshops, these firms probably did not include other important components that were included in the jobsearch workshops investigated by Eden and Aviram (1993) and Vinokur et al. $(1995,2000)$. By other important components, we refer to group problem solving, experiential learning of job-search skills, provision of positive regard and social support to participants by the trainer, and active inoculation against setbacks. We regard the relative absence of these components in the job-search workshops under study as the major reason for our failure to support Hypothesis 2, expecting the intervention to influence the level of self-efficacy.

Apparently, the energy doses for behavioral and attitudinal changes in the job-search workshops under study were not sufficiently invigorating for those who were minimally confident in their job-seeking skills after experiencing prolonged unemployment. A lesson that we learned from the job-search workshops under study is that an intervention that is not specifically designed to help unemployed people who are discouraged after experiencing long periods of unemployment in depressed labor markets ultimately may not be of much help. 


\section{Strengths and Limitations of the Present Research}

A major strength of the current study is that we investigated the re-employment success of unemployed people who participated in job-search workshops in a natural setting. Our research was characterized by minimal obtrusiveness of the researchers into ongoing processes in local labor markets. While admittedly, we did not have any control over the actual training that went on in the workshops, the workshops' general content and mode of delivery were standardized. The randomization of respondents into the experimental and control groups allowed us to compare the relative re-employment success of participants in those groups.

A major limitation of this study concerns the external validity of the results obtained. First, only about two thirds of the unemployed persons in the country resorted to the Employment Service for help with their job search (State of Israel, Bureau of Statistics, 2004). The other third - primarily highly qualified professional and technical workers-was underrepresented in our sample. Second, the job-search workshops under study were conducted only in pockets of high unemployment, located in the peripheral areas of the country, so our findings cannot be generalized to unemployed people in other areas of the country. Third, we did not cover unemployed youth, IsraeliArabs and unemployed recent immigrants, for the reasons detailed in the Method section.

A potential threat to the internal validity of this field experiment stems from our lack of control over the actual delivery of the workshops; namely, the training processes that were employed in the workshops. We made the reasonable assumption that the workshops were held in accordance with the terms and conditions of the general contract issued by the Ministry of Labor and Social Welfare insofar as their content is concerned. The manipulation checks indicated that the workshop experience was highly regarded by the vast majority of participants. Still, we did not control the training of the workshops' trainers, nor their actual training process. This is a common feature of studies that assess the efficacy of interventions for unemployed persons designed and carried out by a government agency (e.g., Creed et al., 1999; Salipante \& Goodman, 1976; Vuori \& Vesalainen, 1999).

Yet, an additional limitation of the study involves the assessment of the intervention in terms of endpoints related to re-employment/unemployment, rather than changes in job-search behaviors that presumably led to these endpoints. However, the intervention was multifocal, and its effects on jobsearch behaviors tend to be complex and probably nonlinear. For example, it is quite possible for the intervention to have a negative effect on certain job-search behaviors, but positive effects on re-employment outcomes. For example, consider a person searching a new job more efficaciously by limiting 
the number of job interviews only to the ones considered most promising. This is one reason for our focus on re-employment outcomes in assessing the effectiveness of the intervention under study.

Our findings suggest that the efficacy of the job-search workshop intervention may be further increased through redesign to enhance and promote participants' self-efficacy. This can be accomplished by including components likely to enhance self-efficacy in the design of the intervention, like those incorporated in the workshops investigated by Vinokur et al. (1995, 2000). These components include training workshops' trainers to act as role models to encourage more effective job-search strategies, instructing the workshops' trainers to offer experiential learning that involves the participants in each stage of the process, and having participants field-test their acquired skills under conditions likely to breed positive performance feedback. These components necessitate intensive training to the trainers.

In sum, the findings of this study suggest that the wide array of interventions aimed at helping people to cope with difficult behavioral changes under stressful life circumstances can be improved by adopting the design and delivery guidelines formulated in this section. Future research should explore this possibility, such as having trainers in government-initiated and supported job-search workshops for unemployed persons provide sufficient encouragement, support, and attention in the workshops to participants, thereby enhancing their self-efficacy.

\section{References}

Aiken, L. A., \& West, S. G. (1991). Multiple regression: Testing and interpreting interactions. Newbury Park, CA: Sage.

Bandura, A. (1997). Self-efficacy: The exercise of control. New York: W. H. Freeman.

Bandura, A., \& Wood, R. E. (1989). Effect of perceived controllability and performance standards on self-regulation of complex decision-making. Journal of Personality and Social Psychology, 56, 805-814.

Barling, J. (1990). Employment, stress, and family functioning. New York: John Wiley \& Sons.

Bloom, H. S. (1984). Accounting for no-shows in experimental evaluation designs. Evaluation Review, 8, 225-246.

Brown, D. J., Cober, R. T., Kane, K., Levy, P. E., \& Shalhoop, J. (2006). Proactive personality and the successful job search: A field investigation with college graduates. Journal of Applied Psychology, 91, 717-726.

Caplan, R. D., Vinokur, A. D., Price, R. H., \& van Ryn, M. (1989). Job seeking, re-employment, and mental health: A randomized field 
experiment in coping with job loss. Journal of Applied Psychology, 74, 759-769.

Clark, M. M., Abrams, D. B., Niaura, R. S., Eaton, C. A., \& Rossi, J. S. (1991). Self-efficacy in weight management. Journal of Consulting and Clinical Psychology, 59, 739-744.

Cook, T. D., \& Campbell, D. T. (1979). Quasi-experimentation: Design and analysis issues for field settings. Boston: Houghton Mifflin.

Cote, S., Saks, A. M., \& Zikic, J. (2006). Trait affect and job search outcomes. Journal of Vocational Behavior, 68, 233-252.

Creed, P. A., Hicks, R. E., \& Machin, M. A. (1999). Behavioural plasticity and mental health outcomes for the long-term unemployed attending occupational training programmes. Journal of Occupational and Organizational Psychology, 71, 171-191.

Davidson, C., \& Woodbury, S. A. (1993). The displacement effect of re-employment bonus programs. Journal of Labor Economics, 11, 575606.

Dvir, T., Eden, D., \& Banjo, M. L. (1995). Self-fulfilling prophecy and gender: Can women be Pygmalion and Galatea? Journal of Applied Psychology, 80, 253-270.

Eden, D., \& Aviram, A. (1993). Self-efficacy training to speed re-employment: Helping people to help themselves. Journal of Applied Psychology, 78, 352-360.

Eden, D., \& Kinnar, J. (1991). Modeling Galatea: Boosting self-efficacy to increase volunteering. Journal of Applied Psychology, 76, 770-780.

Feather, N. T. (1990). The psychological impact of unemployment. New York: Springer-Verlag.

Gist, M. E., Stevens, C. K., \& Bavetta, A. G. (1991). Effects of self-efficacy and post-training intervention on the acquisition and maintenance of complex interpersonal skills. Personnel Psychology, 44, 837-861.

Hansen, W. B., Collins, L. M., Malotte, C. K., Johnson, C. A., \& Fielding, J. E. (1985). Attrition in prevention research. Journal of Behavioral Medicine, 8, 261-275.

Judge, T. A., \& Bono, J. E. (2001). Relationship of core self-evaluation traits (self-esteem, generalized self-efficacy, locus of control, and emotional stability) with job satisfaction and job performance: A meta-analysis. Journal of Applied Psychology, 86, 80-92.

Kanfer, R., Wanberg, C. R., \& Kantrowitz, T. M. (2001). Job search and employment: A personality-motivational analysis and meta-analytic review. Journal of Applied Psychology, 86, 837-855.

Leana, C. R., \& Feldman, D. C. (1995). Finding new jobs after a plant closing: Antecedents and outcomes of the occurrence and quality of re-employment. Human Relations, 48, 1381-1401. 
Little, R. J., \& Yau, L. H. Y. (1998). Statistical technique for analyzing data from prevention trials: Treatment of no-shows using Rubin's causal model. Psychological Methods, 3, 147-159.

Moynihan, L. M., Roehling, M. V., LePine, M. A., \& Boswell, W. R. (2003). A longitudinal study of the relationships among job-search self-efficacy, job interviews, and employment outcomes. Journal of Business and Psychology, 18, 207-233.

McKee-Ryan, F. M., Song, Z., Wanberg, C. R., \& Kinicki, A. J. (2005). Psychological and physical well-being during unemployment: A metaanalytic study. Journal of Applied Psychology, 90, 53-76.

Ozer, E. M., \& Bandura, A. (1990). Mechanisms governing empowerment effects: A self-efficacy analysis. Journal of Personality and Social Psychology, 58, 472- 486.

Patton, W., \& Donohue, R. (1998). Coping with long-term unemployment. Journal of Community and Applied Social Psychology, 8, 331-343.

Payne, R. L., \& Jones, G. (1987). The effects of long-term unemployment on attitudes to unemployment. Journal of Organizational Behavior, 8, 351358.

Pearlin, L. I., \& Schooler, C. (1978). The structure of coping. Journal of Health and Social Behavior, 19, 2-21.

Pedhazur, E. J. (1982). Multiple regression in behavioral research: Explanation and prediction $\left(2^{\text {nd }}\right.$ ed.). New York: Holt, Rinehart, \& Winston.

Price, R. H., van Ryn, M., \& Vinokur, A. D. (1992). Impact of preventive job search intervention on the likelihood of depression among the unemployed. Journal of Health and Social Behavior, 33, 158-167.

Salipante, P., Jr., \& Goodman, P. (1976). Training, counseling, and retention of the hard-core unemployed. Journal of Applied Psychology, 61, 1-12.

Scheier, M. F., \& Carver, C. S. (1987). Dispositional optimism and physical well-being: The influence of generalized outcome expectancies on health. Journal of Personality, 55, 169-210.

Scheier, M. F., \& Carver, C. S. (1992). Effects of optimism on psychological and physical well-being: Theoretical overview and empirical update. $\mathrm{Cog}$ nitive Therapy and Research, 16, 201-228.

Shadish, W. R. (2002). Revisiting field experimentation: Field notes for the future. Psychological Methods, 7, 3-19.

Sherer, M., \& Adams, C. H. (1983). Construct validation of the self-efficacy scale. Psychological Reports, 53, 899-902.

Smith, R. (1989). Effects of coping skills training on generalized self-efficacy and locus of control. Journal of Personality and Social Psychology, 56, $228-233$.

State of Israel, Bureau of Statistics. (2004). Israel's yearbook of statistics. Jerusalem: Author. 
Tipton, R., \& Worthington, E., Jr. (1984). The measurement of generalized self-efficacy: A study of construct validity. Journal of Personality Assessment, 48, 545-548.

Twisk, J. W. R. (2003). Applied longitudinal data analysis of epidemiology. Cambridge, UK: Cambridge University Press.

Vinokur, A., \& Caplan, R. D. (1987). Attitudes and social support: Determinants of job-seeking behavior and well-being among the unemployed. Journal of Applied Social Psychology, 17, 1007-1024.

Vinokur, A. D., Price, R. H., \& Schul, Y. (1995). Impact of the JOBS intervention on unemployed workers varying in risk for depression. American Journal of Community Psychology, 23, 39-74.

Vinokur, A. D., \& Schul, Y. (1997). Mastery and inoculation against setbacks as active ingredients in the JOBS intervention for the unemployed. Journal of Consulting and Clinical Psychology, 65, 867-877.

Vinokur, A. D., Schul, Y., Vuori, J., \& Price, R. H. (2000). Two years after a job loss: Long-term impact of the JOBS Program on re-employment and mental health. Journal of Occupational Health Psychology, 5, 32-48.

Vinokur, A. D., van Ryn, M., Gramlich, E. M., \& Price, R. H. (1991). Long-term follow-up and benefit-cost analysis of the JOBS Program: A preventive intervention for the unemployed. Journal of Applied Psychology, 76, 213-219.

Vuori, J., \& Vesalainen, J. (1999). Labour market interventions as predictors of re-employment, job-seeking activity, and psychological distress among the unemployed. Journal of Occupational and Organizational Psychology, $72,523-538$.

Wanberg, C. R. (1997). Antecedents and outcomes of coping behaviors among unemployed and re-employed individuals. Journal of Applied Psychology, 82, 731-744.

Warr, P. B., \& Jackson, P. R. (1987). Adapting to the unemployed role: A longitudinal investigation. Social Science and Medicine, 25, 1219-1224.

Wenzel, S. L. (1993). The relationship of psychological resources and social support to job procurement self-efficacy in the disadvantaged. Journal of Applied Social Psychology, 23, 1471-1497.

Winefield, A. H., \& Tiggemann, M. (1990). Length of unemployment and psychological distress: Longitudinal and cross-sectional data. Social Science and Medicine, 31, 461-465.

Wood, R., \& Bandura, A. (1989). Impact of conceptions of ability on selfregulatory mechanisms and complex decision making. Journal of Personality and Social Psychology, 56, 407-415. 